\title{
A Study of Platelet Indices in Type 2 Diabetes Mellitus Patients
}

\author{
Kumari Shilpi $^{1}$ (1) $\cdot$ R. M. Potekar ${ }^{1}$
}

Received: 29 April 2016/Accepted: 2 May 2017/Published online: 8 May 2017

(C) Indian Society of Haematology \& Transfusion Medicine 2017

\begin{abstract}
Altered platelets have been reported in patients with diabetes mellitus and has been considered as a 'prothrombotic state' with enhanced platelet reactivity. They have been associated with increased risk of vascular complications in these patients. Platelet indices correlate with functional status of platelets and is an emerging risk factor of vascular complications in diabetes. The study was undertaken to know the efficacy of platelet analysis in assessing the prognosis of diabetes mellitus. A prospective hospital based study of platelet parameters MPV, PDW and P-LCR was carried out on 280 cases diagnosed with Type 2 diabetes Mellitus and 280 controls with normal blood glucose levels. The blood glucose levels and HbA1c level were also measured. Statistical evaluation was performed by using Student's unpaired $t$ test and Pearson correlation test. The average age of presentation with type 2 diabetes mellitus was $53 \pm 5.7$ years. The mean duration of diabetes was $4.7 \pm 2.5$ years. MPV, PDW and P-LCR were significantly higher in diabetics compared to non diabetics $(11.3 \pm 1.0$ vs. $9.0 \pm 0.6,14.2 \pm 2.5$ vs. $10.7 \pm 0.7 \mathrm{fl}$, $35.0 \pm 8.1$ vs. $23.0 \pm 2.4 \%$ ). Among the diabetics, MPV, PDW and P-LCR were higher in those with complications as compared to those without complications, which was not statistically significant. The higher values of MPV, PDW and P-LCR indicates that they serve as better risk indicator
\end{abstract}

Kumari Shilpi

dr.shilpi2004@gmail.com

1 Department of Pathology, Shri. B.M. Patil Medical College, Hospital and Research Centre, Solapur road, Vijayapura, Karnataka 586103, India of initial vascular complications in diabetes mellitus patients and can be used as a simple and cost effective tool to assess vascular events.

Keywords Mean platelet volume $\cdot$ Platelet distribution width Platelet-large cell ratio $\cdot$ Diabetes mellitus

\section{Introduction}

\section{Definition}

World Health Organization (WHO) defines diabetes mellitus (DM) as a metabolic disorder of multiple aetiology characterized by chronic hyperglycemia with disturbances of carbohydrate, fat and protein metabolism resulting from defects in insulin secretion, insulin action, or both. Diabetes Mellitus currently affects more than 171 million people worldwide and will affect an estimated 366 million by 2030 . India will be the country with the maximum number of diabetics in the world by 2030. In 2014, 40.9 million people were affected with diabetes in India and the projected estimate for the year 2030 is 80 million [1].

People with diabetes, exhibit increased platelet reactivity. Hyperglycemia contributes to greater platelet reactivity through direct effects and by promoting glycation of platelet proteins. Both insulin resistance and insulin deficiency increase platelet reactivity. Insulin inhibits activation of platelets. Therefore, relative or absolute deficiency of insulin would increase platelet reactivity [2].

Mean platelet volume (MPV) is an indicator of average size and activity of the platelets and is reported to be high in diabetes mellitus and is considered as a risk factor for heart disease. Similarly platelet distribution width (PDW) is an indicator of variation in platelet size which may be a 
sign of active platelet release. Platelet large cell ratio (PLCR) is directly related to PDW and MPV [3].

Although several measurements of platelet activity have emerged as potential contributors to atherothrombosis, many of them are time consuming, expensive and use a high sample volume. Alternatively, MPV, PDW and P-LCR can be easily determined on routine automated hemograms available at low cost. Patients with larger platelets can easily be identified during routine haematological analysis and timely treatment could be undertaken.

\section{Materials and Methods}

\section{Ethics Approval was Granted by the Institution}

A cross sectional hospital based study was carried out on 280 diagnosed cases of Type 2 DM from November 2013 to June 2015 fulfilling the inclusion and exclusion criteria attending either outpatient or inpatient department and compared with 280 controls with normal blood glucose levels. The prevalence rate of diabetes mellitus in India was taken as $9.3 \%$ [4]. At $95 \%$ confidence interval and $\pm 5 \%$ margin of error, the required sample size was calculated using the statistical formula

$n=\frac{(Z \alpha)^{2} p \times q}{d^{2}}$

$Z \alpha=1.96$ for $\alpha$ value; Where $p$ : prevalence rate, $q=100-p ; d$ : margin of error.

Cut off values of platelet indices have been derived by calculating the minimum value of these indices in the diabetic cases. All the diabetic and nondiabetic subjects were interviewed as per the prepared proforma and underwent a complete clinical evaluation with specific reference to any associated macro-or microvascular complications as well as any drugs taken. Relevant investigations like blood glucose levels and $\mathrm{HbAlc}$ level was performed for confirmation of the diagnosis. The instrument used for $\mathrm{HbA} 1 \mathrm{c}$ and other glucose parameters was Roche Hitachi Cobas c311 (Hitachi Ltd, Tokyo, Japan). The blood samples of the patients were drawn from the antecubital vein using a $5 \mathrm{ml}$ syringe and immediately mixed in EDTA vacuutainers. The sample was run within $2 \mathrm{~h}$ of venepuncture using the five part differentiated automated Hematology analyzer Sysmex XN-1000 (Sysmex Corporation, Kobe, Japan) and complete blood count analysis of the sample was made including the platelet indices (MPV, PDW and P-LCR). Statistical tests used for handling the data was unpaired $t$ test for mean and comparison and also Pearson correlation coefficient to correlate various platelet indices with biochemical parameters. The statistical software used for the study was SPSS Version 24
[International Business Machines Corporation (IBM), United States].

\section{Exclusion Criteria}

Male patients with hemoglobin below $13 \mathrm{gm} \%$ and female patients with $\mathrm{Hb}$ below $12 \mathrm{gm} \%$. Subjects on antiplatelet drugs such as aspirin and clopidogrel and with any diagnosed malignancy were also excluded from the study. After baseline evaluation, diabetic patients were divided into two groups according to their $\mathrm{HbA1c}$ levels: group A consisted of patients with $\mathrm{HbA} 1 \mathrm{c}$ levels $<6.5 \%$ and group B consisted of patients with $\mathrm{HbAlc}$ levels $\geq 6.5 \%$. The latest HbA1c cut-off for diabetic range was considered according to American Diabetic Association 2016 criteria.

\section{Results}

280 Type 2 diabetic cases and 280 controls with normal blood glucose parameters were included in the present study. In the present study, the age ranged from 45 to 70 years. The mean age of diabetic patients in our study was $53 \pm 5.7$ years and that of the control group was $54.1 \pm 5.2$ years. Majority of the patients diagnosed with Type $2 \mathrm{DM}$ belonged to 5 th decade of life. The mean duration of diabetes was $4.7 \pm 2.5$ years. In the present study total number of males including both cases and controls were $315(56.25 \%)$ and total number of females were $245(43.75 \%)$. The number of males in the diabetic group were 144 (51.43\%) compared to $171(64.57 \%)$ in non-diabetic group. The numbers of females in diabetics were $136(48.57 \%)$ compared to 109 in non diabetics.

Out of 280 patients in the present study, 117 (41.79\%) patients had complications such as diabetic foot, hypertension, coronary artery disease, diabetic retinopathy, diabetic nephropathy, autonomic neuropathy, peripheral neuropathy, peripheral vascular disease, hypercholesterolemia and hypertriglyceridemia and 163 (58.21\%) cases did not present with complications. Sixty-nine of the 144 males and forty-eight of the 136 females had diabetic complications.

The blood glucose parameters (FBS, RBS, PPBS and HbA1c) were statistically significantly higher in diabetics compared to the non-diabetics ( $p$ value $<0.001$ ). The MPV, PDW and P-LCR were evaluated in diabetic and non diabetic population. The mean MPV in diabetic cases were $11.3 \pm 1.0 \mathrm{fl}$ compared to $9 \pm 0.6 \mathrm{fl}$ in non diabetics with $p$ value 0.004 . Mean PDW and P-LCR in diabetic patients were $14.2 \pm 2.5 \mathrm{fl}$ and $35.0 \pm 8.1 \%$ compared to non diabetics where it was $10.7 \pm 0.7 \mathrm{fl}$ and $23.0 \pm 2.4 \%$ respectively. Our study observed $p$ value of MPV, PDW 
and P-LCR to be highly significant in diabetic patients $(p<0.05)$ (Table 1).

Among the diabetic subjects, a positive statistical Pearson correlation was observed between MPV, PDW and P-LCR with HbA1c, FBS, RBS, PPBS, and complications. However, no statistical correlation was seen between MPV, PDW and P-LCR and the duration of DM in the diabetic group (Table 2).

Diabetic patients were also divided into two groups after baseline evaluation according to their HbAlc level. Out of 280 Type 2 DM cases, there were 60 patients $(21.43 \%)$ in group A (mean $\mathrm{HbA} 1 \mathrm{c}<6.5 \%$ ) and 220 patients $(78.57 \%$ ) in group B. The mean MPV in group B $(11.7 \pm 1.0 \mathrm{fl})$ was significantly higher in group A $(11.1 \pm 1.2 \mathrm{fl})$. Significantly higher mean PDW in group B (14.3 $\pm 2.4 \mathrm{fl})$ was observed in our study compared to group A (13.5 $\pm 2.7 \mathrm{fl})$. Our study also observed stastistical significant difference between mean P-LCR in group B $(35.6 \pm 7.7 \%)$ than group A $(32.7 \pm 9.1 \%)$. Duration of diabetes was not statistically significant between groups $\mathrm{A} \& \mathrm{~B}$ ( $p$ value 0.746) (Table 3).

Platelet indices were also compared between diabetic patients with and without complications. Although the mean of MPV, PDW and P-LCR was higher in diabetics with complications $(11.5 \pm 1.4, \quad 14.4 \pm 2.7 \mathrm{fl}$ and $35.9 \pm 8.3 \%)$ than without complications (11.3 \pm 1.0 ,
$13.9 \pm 2.1 \mathrm{fl}$ and $34.4 \pm 7.8 \%$ ) it was not statistically significant ( $p$ value of MPV $=0.105, \mathrm{PDW}=0.098$ and P-LCR $=0.104$; Table 4).

\section{Discussion}

Diabetes mellitus is not a single disease entity but rather a group of metabolic disorders sharing the common underlying feature of hyperglycemia. The chronic hyperglycemia and metabolic dysregulation may be associated with secondary damage in multiple organ systems, especially the kidneys, eyes and blood vessels [5].

Diabetes mellitus is a major global health problem [6]. India leads the world with largest number of diabetic subjects earning the dubious distinction of being termed the "diabetes capital of the world". It is one of the major causes of morbidity and mortality affecting youth and middle aged people in India [5]. The mean age of onset is 42.5 years. The estimated prevalence of Impaired Glucose Tolerance (IGT) is thought to be around 8.7 and $7.9 \%$ in urban and rural areas. It is thought that around $35 \%$ of IGT sufferers go on to develop type 2 diabetes so India is genuinely facing a healthcare crisis [7].

Therefore, preventing vascular complications and monitoring of DM are the need of the hour. Type 2 DM
Table 1 Comparison of mean of blood sugar and platelet indices among diabetic cases and non-diabetic controls

\begin{tabular}{lccc}
\hline Parameters & $\begin{array}{l}\text { Diabetic }(\mathrm{n}=280) \\
\text { Mean } \pm \mathrm{SD}\end{array}$ & $\begin{array}{l}\text { Non-diabetic }(\mathrm{n}=280) \\
\text { Mean } \pm \mathrm{SD}\end{array}$ & $\begin{array}{l}t \text { test } \\
p \text { value }(2 \text { tailed })\end{array}$ \\
\hline HbA1c (\%) & $7.3 \pm 1.1$ & $3.3 \pm 0.4$ & 0.004 \\
FBS (mg/dl) & $158.1 \pm 33.7$ & $81.7 \pm 5.1$ & 0.002 \\
RBS (mg/dl) & $214.2 \pm 42.1$ & $118.3 \pm 20.6$ & 0.002 \\
PPBS (mg/dl) & $235.6 \pm 38.5$ & $145.8 \pm 9.2$ & 0.005 \\
MPV (fl) & $11.3 \pm 1.0$ & $9.0 \pm 0.6$ & 0.004 \\
PDW (fl) & $14.2 \pm 2.5$ & $10.7 \pm 0.7$ & 0.003 \\
P-LCR (\%) & $35.0 \pm 8.1$ & $23.0 \pm 2.4$ & 0.002 \\
\hline
\end{tabular}

Table 2 Correlation of MPV, PDW and P-LCR with various parameters studied among diabetic cases

\begin{tabular}{|c|c|c|c|c|c|c|}
\hline \multirow[t]{2}{*}{ Characteristics } & \multicolumn{2}{|l|}{ MPV (fl) } & \multicolumn{2}{|l|}{ PDW (fl) } & \multicolumn{2}{|l|}{ P-LCR (\%) } \\
\hline & $\begin{array}{l}\text { Correlation coefficient } \\
(r \text { value })\end{array}$ & $p$ value & $\begin{array}{l}\text { Correlation coefficient } \\
(r \text { value })\end{array}$ & $p$ value & $\begin{array}{l}\text { Correlation coefficient } \\
(r \text { value })\end{array}$ & $p$ value \\
\hline HbA1c (\%) & 0.148 & $<0.001$ & 0.171 & $<0.001$ & 0.164 & $<0.001$ \\
\hline FBS (mg/dl) & 0.055 & $<0.01$ & 0.098 & $<0.001$ & 0.091 & $<0.001$ \\
\hline RBS (mg/dl) & 0.011 & $<0.001$ & 0.049 & $<0.05$ & 0.021 & $<0.02$ \\
\hline PPBS (mg/dl) & 0.029 & $<0.05$ & 0.075 & $<0.02$ & 0.052 & $<0.05$ \\
\hline $\begin{array}{l}\text { Duration of diabetes } \\
\text { (years) }\end{array}$ & 0.126 & 0.538 & 0.161 & 0.553 & 0.140 & 0.148 \\
\hline Complications & 0.097 & $<0.05$ & 0.099 & $<0.02$ & 0.097 & $<0.001$ \\
\hline
\end{tabular}


Table 3 Comparison of diabetic cases in group A and group B

\begin{tabular}{|c|c|c|c|}
\hline Parameters & $\begin{array}{l}\text { Group A Hba1c }<6.5 \%(\mathrm{n}=60) \\
\text { Mean } \pm \text { SD }\end{array}$ & $\begin{array}{l}\text { Group B Hba1c } \geq 6.5 \%(n=220) \\
\text { Mean } \pm \text { SD }\end{array}$ & $\begin{array}{l}t \text { test } \\
p \text { value }(2 \text {-tailed })\end{array}$ \\
\hline Age (years) & $50.2 \pm 5.6$ & $53.8 \pm 5.5$ & 0.001 \\
\hline MPV (fl) & $11.1 \pm 1.2$ & $11.7 \pm 1.0$ & 0.024 \\
\hline PDW (fl) & $13.5 \pm 2.7$ & $14.3 \pm 2.4$ & 0.022 \\
\hline P-LCR (\%) & $32.7 \pm 9.1$ & $35.6 \pm 7.7$ & 0.013 \\
\hline FBS (mg/dl) & $137.9 \pm 12.4$ & $163.7 \pm 35.5$ & 0.002 \\
\hline RBS (mg/dl) & $183.5 \pm 17.6$ & $222.6 \pm 42.9$ & 0.004 \\
\hline PPBS (mg/dl) & $212.1 \pm 24.7$ & $242.1 \pm 39.1$ & 0.001 \\
\hline Duration of diabetes (Years) & $3.4 \pm 1.6$ & $3.6 \pm 1.7$ & 0.746 \\
\hline
\end{tabular}

Table 4 Comparison of selected parameters among diabetic patients with and without complications

\begin{tabular}{lccc}
\hline Parameters & $\begin{array}{l}\text { Complications absent }(\mathrm{n}=163) \\
\text { Mean } \pm \text { SD }\end{array}$ & $\begin{array}{l}\text { Complications present }(\mathrm{n}=117) \\
\text { Mean } \pm \text { SD }\end{array}$ & $\begin{array}{l}t \text { test } \\
p \text { value }(2 \text {-tailed })\end{array}$ \\
\hline MPV (fl) & $11.3 \pm 1.0$ & $11.5 \pm 1.4$ & 0.105 \\
PDW (fl) & $13.9 \pm 2.1$ & $14.4 \pm 2.7$ & 0.098 \\
P-LCR (\%) & $34.4 \pm 7.8$ & $35.9 \pm 8.3$ & 0.104 \\
HbA1c (\%) & $7.0 \pm 1.0$ & $7.8 \pm 1.1$ & 0.005 \\
FBS (mg/dl) & $149.6 \pm 24.2$ & $168.9 \pm 36.3$ & 0.004 \\
RBS (mg/dl) & $200.9 \pm 30.6$ & $227.9 \pm 43.1$ & 0.007 \\
PPBS (mg/dl) & $225.3 \pm 26.9$ & $266.8 \pm 43.0$ & 0.002 \\
Duration of diabetes (Years) & $3.3 \pm 1.3$ & $6.7 \pm 2.3$ & 0.025 \\
\hline
\end{tabular}

accounts for $90-95 \%$ of all DM cases. They exhibit insulin resistance and consequent hyperinsulinemia for 10-20 years before manifesting diabetes. Deficient insulin action is the cardinal factor for development of DM and clearly contributes to platelet dysfunction [8].

Platelets from patients with type 2 diabetes mellitus have increased reactivity and baseline activation which are likely to play a key role in development and sustainment of vascular complications [9]. Sustained hyperglycemia leads to a series of interrelated alterations that can cause evident endothelial dysfunction and vascular complications. Moreover, hyperglycaemia-induced up-regulation of glycoproteins ( $\mathrm{Ib}$ and IIb/IIIa), and P2Y12 signalling which are key events underlying atherothrombotic risk in T1DM and T2DM [10]. Formation of advanced glycation end products, activation of protein kinase $\mathrm{C}$ and disturbances in polyol pathways are the possible mechanisms by which increased glucose induces vascular abnormalities [11].

Human platelets are anucleate discoid cells that circulate in the bloodstream and participate in hemostasis. In response to stimuli generated by the endothelium of blood vessels, platelets change shape, adhere to subendothelial surfaces, secrete the contents of intracellular organelles, and aggregate to form a thrombus [12]. Higher MPV in diabetic patients indicates larger platelet size suggesting stimulated thrombopoiesis and augmented platelet activation [13]. Platelet hyperactivity is accompanied by an increased production of thromboxaneA2, serotonine, thromboglobulin or a decreased synthesis of prostacycline. One possible mechanism of increased MPV in DM is osmotic swelling due to raised blood glucose and perhaps due to a shorter life span of platelets in diabetic patients [14].

In our study, the MPV was significantly higher in the diabetic group than the nondiabetic controls which was similar to the studies done by other researchers (Table 5). In an earlier study by Akinsegun et al. [18] showed lower MPV in diabetic cases compared to the controls with no statistical significant difference.

In addition, other platelet indice PDW was also significantly higher in diabetic subjects compared to controls ( $p 0.003$ respectively). Similar results were noted in other studies done by Demirtas et al. [22], Jabeen et al. [23] and Dalamaga et al. [24] with significantly higher PDW levels among diabetic cases (Table 6).

The P-LCR is not often quoted in literature, probably because it is relatively a new platelet volume parameter. It is generated by only a few machines, with the Sysmex analyser being one of them. Our study concluded that P-LCR was significantly higher ( $p$ value 0.002 ) in diabetic 
Table 5 Comparison of MPV with other studies

\begin{tabular}{llccccc}
\hline Publication & Cell counter & Cases & MPV (fl) & Controls & MPV (fl) & $p$ value \\
\hline Kodiatte et al. [11] & Beckman coulter Act5Diff & 300 & 8.29 & 300 & 7.47 & $<0.001$ \\
Jindal et al. [15] & Sysmex SF 3000 & 75 & 12.08 & 50 & 11.42 & $<0.05$ \\
Zuberi et al. [16] & Sysmex autoanalyzer & 204 & 9.34 & 204 & 8.63 & 0.000 \\
Demirtunc et al. [17] & Cell Dyn 3500 & 70 & 8.7 & 40 & 8.2 & 0.002 \\
Akinsegun et al. [18] & Sysmex KN-21 N & 100 & 8.69 & 100 & 8.91 & 0.593 \\
Ozder and Eker [19] & Sysmex 1800t & 201 & 10.66 & 201 & 10.04 & $<0.001$ \\
Ulutas et al. [20] & Abbott cell dyn 3200 & 65 & 8.3 & 40 & 7.1 & $<0.001$ \\
Papanas et al. [21] & Sysmex SF-3000 & 265 & 14.2 & 151 & 7.1 & 0.01 \\
Present study & Sysmex XN-1000 & 280 & 11.3 & 280 & 9 & $<0.05$ \\
\hline
\end{tabular}

\begin{tabular}{lrlclr}
\hline Publication & Cases & PDW (fl) & Controls & PDW (fl) & $p$ value \\
\hline Demirtas et al. [22] & 307 & 16.4 & 187 & 15.4 & $<0.001$ \\
Jabeen et al. [23] & 170 & 15.02 & 92 & 14.12 & 0.003 \\
Dalamaga et al. [24] & 30 & 16.4 & 30 & 13.0 & $<0.001$ \\
Present study & 280 & 14.2 & 280 & 10.7 & 0.003 \\
\hline
\end{tabular}

Table 6 Comparison of PDW with other studies control improves platelet activity and function and may delay possible diabetic vascular complications.

\section{Limitations of the Study}

Follow up of the cases was not possible to determine the prognostic significance of our findings. Platelet function tests could not be conducted on the sample to substantiate our findings further. Patients with qualitative disorders and reactive causes for raised platelets were not assessed that constitute a minor role.

\section{Conclusion}

Our study suggest that increased platelet volume indices and larger platelets contributes to the prothrombotic state in diabetes mellitus. Because larger platelets are hemostatically more active, therefore its presence probably is a risk factor for developing diabetic vascular complications. Platelets with larger platelets can be easily identified during routine hematological analysis as MPV, PDW and P-LCR are generated as by product of the automated blood counts. Hence, MPV, PDW and P-LCR would be a useful prognostic marker of vascular complications in diabetes. Therefore, the derived cut off values of platelet indices MPV, PDW and P-LCR studied for vascular complications to warn the diabetes patients compared to non-diabetics were 9.6, $12.2 \mathrm{fl}$ and $18.4 \%$. However, the increased MPV, PDW and P-LCR as the cause or the end result of vascular complications needs to be further explored. Thus, platelet volume indices MPV, PDW and P-LCR provides an to decrease. Therefore, it may be concluded that glycemic 
important, simple, effortless and cost effective tool which can be useful in predicting an impending thrombotic state and vascular complications of diabetes.

Acknowledgements Granted by the institution B.L.D.E.U'S Shri.B.M.Patil Medical College, Hospital and Research Centre, Vijayapura.

\section{Compliance with Ethical Standards}

Conflict of interest Author Dr. Kumari Shilpi declares that she has no conflict of interest. Author Dr. R. M. Potekar declares that he has no conflict of interest.

Ethical Approval All procedures performed in studies involving human participants were in accordance with the ethical standards of the institutional and national research committee and with the 1964 Helsinki declaration and its later amendments or comparable ethical standards.

Informed Consent Informed consent was obtained from all individual participants included in the study.

\section{References}

1. Alberti KGMM, Zimmet PZ, World Health Organization (2015) Definition, diagnosis and classification of diabetes mellitus and its complications: report of a WHO consultation. Part 1. Diagnosis and classification of diabetes mellitus. Geneva. Diabet Med 15:539-553

2. Keating FK, Sobel BE, Schneider DJ (2003) Effects of increased concentrations of glucose on platelet reactivity in healthy subjects and in patients with and without diabetes. Am J Cardiol 92:1362-1365

3. Mishra J, Shah P, Sanil R (2012) Hematological disorders from The Kota Tribes of the Nilgris, India. Asian J Biochem Pharm Res 2:156-162

4. Yesudian C, Grepstad M, Visintin E, Ferrario A (2014) The economic burden of diabetes in India: a review of the literature. Glob Health 10:1-18

5. Genuth S, Alberti KG, Bennett P, Buse J, Defronzo R, Kahn R et al (2003) Expert committee on the diagnosis and classification of diabetes mellitus2. Follow-up report on the diagnosis of diabetes mellitus. Diabetes Care 26:3160-3167

6. Hekimsoy Z, Payzin B, Ornek T, Kandoğan G (2004) Mean platelet volume in type 2 diabetic patients. J Diabet Complicat 18:173-176

7. Gaikwad A, Kanitkar S, Kalyan M, Tamakuwala K, Agarwal R, Bhimavarapu B (2014) Prevalence of type 2 diabetes mellitus in candidates contesting for municipal corporation elections in an urban industrialized town. Indian J Basic Appl Med Res $3: 412-418$

8. Hers I (2007) Insulin-like growth factor-1 potentiates platelet activation via the IRS/PI3Kalpha pathway. Blood 110:4243-4252

9. Stratmann B, Tschoepe D (2005) Pathobiology and cell interactions of platelets in diabetes. Diab Vasc Dis Res 2:16-23
10. Mowafy N, Metwaly E, Hashish B, Bazeed M (2015) A study of the value of some platelet parameters in patients with type 2 diabetes mellitus. Al-Azhar Assiut Med J 13:13-18

11. Kodiatte TA, Manikyam UK, Rao SB, Jagadish TM, Reddy M, Lingaiah HK (2012) Mean platelet volume in type 2 diabetes mellitus. J Lab Phys 14:5-9

12. Italiano JE, Gresele P, Fuster V, Lopez JA (2008) The structure and production of blood platelets. In: Gresele P, Fuster V, Lopez JA, Page CP (eds) Platelets in hematologic and cardiovascular disorders, 1st edn. Cambridge University Press, New York, pp 1-20

13. Chang HA, Hwang HS, Park HK, Chun MY, Sung JY (2010) The role of mean platelet volume as a predicting factor of asymptomatic coronary artery disease. Korean J Fam Med 31:600-606

14. Vinik AI, Erbas T, Park TS, Nolan R, Pittenger GL (2001) Platelet dysfunction in type 2 diabetes. Diabetes Care 24:1476-1485

15. Jindal S, Gupta S, Gupta R, Kakkar A, Singh HV, Gupta K, Singh $S$ (2011) Platelet indices in diabetes mellitus: indicators of diabetic microvascular complications. Hematology 16:86-90

16. Zuberi BF, Akhtar N, Afsar S (2008) Comparison of mean platelet volume in patients with diabetes mellitus, impaired fasting glucose and non-diabetic subjects. Singap Med J 49:114-116

17. Demirtunc R, Duman D, Basar M, Bilgi M, Teomete M, Garip T (2009) The relationship between glycemic control and platelet activity in type 2 diabetes mellitus. J Diabet Complicat 23:89-94

18. Akinsegun A, Olusola D, Sarah J, Olajumoke O, Adewumi A, Majeed O et al (2014) Mean platelet volume and platelet counts in type 2 Diabetes: mellitus on treatment and non-diabetic mellitus controls in Lagos, Nigeria. Pan Afr Med J 18:1-5

19. Ozder A, Eker H (2014) Investigation of mean platelet volume in patients with type 2 diabetes mellitus and in subjects with impaired fasting glucose: a cost-effective tool in primary health care. Int J Clin Exp Med 7:2292-2297

20. Ulutas K, Dokuyucu R, Sefil F, Yengil E, Sumbul A, Rizaoglu H et al (2014) Evaluation of mean platelet volume in patients with type 2 diabetes mellitus and blood glucose regulation: a marker for atherosclerosis. Int J Clin Exp Med 7:955-961

21. Papanas N, Symeonidis G, Maltezos E, Mavridis G, Karavageli E, Vosnakidis T et al (2004) Mean platelet volume in patients with type 2 diabetes mellitus. Platelets 15:475-478

22. Demirtas L, Degirmenci H, Akbas E, Ozcicek A, Timuroglu A, Gure A et al (2015) Association of hematological indicies with diabetes, impaired glucose regulation and microvascular complications of diabetes. Int J Clin Exp Med 8:11420-11427

23. Jabeen F, Rizvi H, Aziz F, Wasti A (2013) Hyperglycemic induced variations in hematological indices in type 2 diabetics. Int J Adv Res 1:322-334

24. Dalamaga M, Karmaniolas K, Lekkab A, Antonakosa G, Thrasyvoulides A, Papadavid E et al (2010) Platelet markers correlate with glycemic indices in diabetic, but not diabetic myelodysplastic patients with normal platelet count. Dis Markers 29:55-61

25. Ashraf S, Ranjan R, Singh S, Singh H, Kudesia M, Sharma R (2017) Diabetes disease burden by platelet indices as possible biomarkers in evaluation of initial vascular risks in grading diabetes mellitus: correlation of platelet dysfunction indices with hematopoietic and biochemical biomarkers in diabetes mellitus. Open J Biochem 1-15 (in press) 